\title{
Hanaoka Seishu no Tsuma (1966): Convention, Form, Color and the Writer
}

\author{
Nina Alia Ariefa \\ \{nina_alia@yahoo.com\} \\ Universitas Indonesia, Indonesia
}

\begin{abstract}
The historical novel Hanaoka Seishu no Tsuma by Ariyoshi Sawako selected as the object of this study shows the use of historical person, Hanaoka Seishu, a surgeon and inventor of anesthesia in Japan as secondary character, and the doctor's wife as the main character. This novel shows simple form and tends to be realistic in its narration. It shows ideological colors around the oppression of the Edo era women, while emphasizing psychological problems regarding the inner upheaval of the main female characters, with a simple plot. This novel flows progressively in a speedy rhythm, narrating the life journey of Kae as Hanaoka Seishu's wife. The most compositions are small and personal events interspersed with many descriptions. The writer, Ariyoshi Sawako, Japanese female writer who has received good education, has a great interest in social issues, thus affecting the ideological color of her works.
\end{abstract}

Keywords: Historical Novels, Form, Realistic, Ideological Themes, Education, The Writing of Historical Novel

\section{Introduction}

Literary works in Japan was generally dominated by male writers before World War II. The atmosphere of female authorship shows its significance after World War II which was marked by the emergence of Japanese women writers in this era. Orbaugh [1] refers to this period as the period of sudden boom in women's writing that occurred on early 1960's to mid 1970's. This period represented a significant cultural moment in which Japanese women writers could explore through fiction the various discourses and power relationships of postwar Japan. This occurrence was driven by a widespread atmosphere of democracy in Japan after the occupation of the United States in Japan (1945-1952) after Japan's defeat in World War II. The enactment of the new Constitution in 1947, which replaced the Meiji Constitution, provided a legal basis for equality of women's and men's rights, thus providing more opportunities for women writers in this era to expressing their voices, compared to their counterparts before World War II. In other words, voices of Japanese women in the past which cannot be expressed, can be voiced through the presence of the works of women writers in this era.

Among those writers who appeared in 1960's to 1970's era, there were some who wrote historical novels as part of their works, including Ariyoshi Sawako (1931-1984). By taking the background and historical figures of the Edo period, the historical novel written by Ariyoshi Sawako can be considered to have a role in reviving the Edo epoch, and being able to provide historical information. Although there are imaginary values, literary works can be an 
alternative source that helps obtaining valuable social data which cannot be obtained from conventional sources. These conventional sources are generally in the form of rigid data, most of which can only show reality on the surface, hence cannot describe the reality that happened in the past [2]. The vast dimension of the functions of historical novels makes literary works inevitable in expressing past realities, which is important to explain events in the past in their entirety. Based on these things, this paper aims to examine one of Ariyoshi Sawako's historical novel entitled Hanaoka Seishu no Tsuma (1966) with a focus on expressing the conventions, shapes, colors and peculiarities of Ariyoshi Sawako's writings as the author. The novel is able to represent historical novels written by Japanese women writers after World War II, in revealing and reflecting on people's lives in the Edo period, an era that is almost a century adrift with the publication of this novel.

\section{Methodology}

Due to the purpose of the research is to reveal the historical novel form of Hanaoka Seishu no Tsuma by Ariyoshi Sawako, a structural approach is considered to be the right method. Structuralism allows us to see the intrinsic elements of a literary work. In detail, this study will use Todorov's theory of syntactic, thematic and verbal aspects [3], as well as Barthes's theory of syntagmatic and paradigmatic relationships summarized in Shlomith Rimmon-Kenan's book [4]. The conventions of historical novels theories are also needed in this study. Djokosujanto [5] stated that the interpretation of historical romance as romance which presenting historical events and figures was inadequate. Therefore, this study uses the different theories of Walter Scott and Lukacs about the genre of the novel in terms of the use of historical figures and events in historical novels. According to Scott's [6] theory which emphasizes the purity of history, historical figures and events must occupy a secondary position as a background, while the main character is played by a fictional character. On the contrary, according to Lukacs [7], historical novels are a reflection of the present in a past, or an attempt to understand/present the present through the past, which means that historical figures can occupy the main characters but their characterization and appearance in action are adjusted to the author's interpretation.

\section{Findings and Discussion}

\subsection{The Convention}

In the historical novel entitled Hanaoka Seishu no Tsuma, Ariyoshi Sawako brought up the story of a Japanese historical figure named Dr. Hanaoka Seishu (1760-1835), the Japanese doctor who successfully performed breast cancer surgery using his formulation anesthetics. Although Ariyoshi raised the historical events related to Dr. Hanaoka in her novel, she prefers to focused on the story of a woman, named Kae, the wife of Dr. Hanaoka, and other supporting female characters in Hanaoka family, who struggled for supporting him in achieving his dreams.

This novel uses historical figures as main and complementary figures. Based on this, if reviewed based on two historical conventions, the novel follows the Lukacs version of the historical convention that historical figures can occupy the main character but their 
appearance in their action is adjusted to the author's interpretation. This can be seen in the depiction of a figure of Dr. Hanaoka's wife, Kae, who volunteered as the brave first human subject to test the new drug. She consequently went blind from repeated experimentation, likely from anticholinergic toxicity, leaving Dr. Hanaoka with the guilt of his wife's misfortune and the disappointment of another failed attempt at creating the anesthetic he was pursuing so relentlessly [8]. Although mentioned as a historical figure, but the name Kae is not the center of attention in Japanese historical records. She became a supporting figure for Dr. Hanaoka in Japanese history.

The portrayal of the character and appearance of Kae developed based on Ariyoshi's interpretation appeared throughout the novel, starting from the depiction of Kae in her childhood, until her old age. Following are a few excerpts from Ariyoshi's description of Kae's character in three periods.

That same day, Kae, bursting with an enthusiasm she could scarcely control, related the incident to her mother, concealing nothing since she did not think it was wrong to have visited Hirayama. Her mother nodded in an approving manner and offered an additional comment of her own. (p. 5)

When Kae found out where the money was going, she felt compelled to get Otsugi's permission to weave. Her request was readily granted. After giving her a detailed lesson on operating the shuttle, her mother-in-law warned her not to hurry or the threads would tangle. ... Kae worked hard to show her gratitude, and was soon producing at least five inches of cloth every day. Her natural dexterity and knowledge of embroidery encouraged her to rearrange the threads, so that after a while she was creating original, imaginative patterns. (p. 40)

She began to remember past conversations concerning breast surgery: the first night of Seishu's return from Kyoto, and the time he was in agony knowing that he lacked the technique to operate successfully on his sister's cancer. Kae pictured herself sitting next to Okatsu who was close to death, her breasts enlarged, swollen like overripe pumpkins by comparison with her own small ones. Whispering her name, she prayed now to the woman who had been dead over ten years. ... Kae tried to visualize her husband-red-eyed and breathing hard as be washed the wound of the woman lying on the huge oilcloth, clotted the blood, applied an anesthetic, and finally sewed her up again. Her prayers lasted for quite a while. She was not praying for the woman's recovery; nor, in fact, did she make any concrete wishes. All she desired was that Seishu discover a new purpose in life so that he might become involved in something as meaningful to him as his work on anesthetics. (p. 155)

The three quotations above illustrate the character of Kae, starting at the age of 8 years, 21 years when she entered the Hanaoka family, until the age of 44 years. The development of Kae's character was developed-based on Ariyoshi's interpretation as the author, which was adjusted to the narrative needs in the novel.

In total, the number of characters in this novel numbered 50 people. Djokosujanto [5] explains that the sheer number of characters is actually a common but facultative characteristic of a historical novel. Historical novels inevitably need a lot of characters because it tells historical events that are full of intrigue. This novel mentioned a number of 
historical figures in world medical science development, which described as a role model or reference source regarding to Dr. Hanaoka.

\subsection{The Form}

The meaning of the form in this study is the Hanaoka Seishu no Tsuma's composition or structure. The novel is divided into 15 parts, each of which tells a concise story of certain events that took place in Kae's life. The plot in this novel flows progressively in a simple form. The narrator tells the beginning of the story, which began when the character of Kae at the age of 8 saw Otsugi, who was very beautiful and elegant for the first time. Kae was impressed by Otsugi's charm, therefore she grew up as a young girl who worshiped Otsugi's figure. Thirteen years later, Otsugi made a visit to Kae's residence to meet Sajihei, Kae's father, to ask him for Kae to marry Otsugi's eldest son, Seishu. The story revolves around the marriage that took place between Kae and Seishu, and Kae's happy days as a daughter-in-law in her new family. Although she grew up in a well-off family, day by day she devoted herself to her new family by weaving cotton clothes to support the financial needs of her new family and Seishu's tuition in Kyoto. But the story of her happiness and strong bonds with her mother-in-law suddenly changed when Seishu returned to their midst, after completing his medical studies in Kyoto. The cold attitude that Otsugi began to show implicitly to Kae, caused resentment in Kae. Since then, the veiled competition between Kae and Otsugi began and increasingly fierce occurred, until the peak was the two competing to put themselves forward as guinea pigs in an experiment being conducted by Seishu. Kae was blind because of Seishu's concoction after she drunk it on several times trial. The loss of Kae's eyesight, made him guilty, and since then Seishu's attention was focused only for Kae. It marked Kae's victory over Otsugi and became the end of the story.

There are a number of flashbacks that are reflected in the reverie of the main character, but not much, as illustrated in the following quote.

Otsugi quickly finished what she was doing, glared once more at Kae, and left.

Having lost their former vigor, the funnel-shaped mandarage Howers now lay completely lifeless, as if their very spirit had been crushed. As she dried and placed them in a winnow one by one, her thoughts wandered back to that first night with her husband. She blushed, and sighed in relief that her mother-in-law had gone.

It had been so many days after Umpei's return! At that time, it was customary for a samurai family to have separate quarters for husband and wife, but Otsugi could not 'ignore the marital situation indefinitely. One night, avoiding her daughter in law's eyes, she told Kae to go to Umpei's room.... (p. 67)

In general, this novel has a storyline in a speedy rhythm, which is marked by the leaps of time at each beginning of the section with various time jump intervals. As illustrated in the following quote.

One beautiful spring day, the birds were chirping peacefully and the water splashed merrily as Kae washed clothes by the well. The famine was now only a 
memory. Even the problems of the previous Kishu lord, Harusada Kagenin, belonged to history. (p. 101)

It was the leaps of time that made the story in the novel whose narrative span reaches 79 years flow speedily. Even so, small events with many descriptions fill the composition on it. As seen in the following quote.

Curious as to the fate of the herb garden, Kae walked in the drizzle, hoping for a heavy downpour that would match the intensity of her emotions.... Water was excellent for these herbs, which were really wild plants, and they were sprouting even more profusely than the weeds. Kae was amazed to find some flowers blooming and leaves branching of in all directions. The Korean Morning Glories, almost a transparent white in color, swam in a sea of green. How plentiful were these Crazy Eggplants! Poisonous, vigorous, multiplying rapidly as their seeds dispersed everywhere, of all the herbs in the garden these purple-stemmed ones were the hardiest. Their white flowers, so graceful and lovely from a distance, revealed strong, sharp-edged petals up close. Kae despised them since they never failed to remind her of the first time, she saw Otsugi, and such recollections now provoked her anger. (p. 64)

The 'I' novel or watakushi-shosetsu, which is dominant in Japanese literature in particular has been well adapted for the needs of Japanese female writers [9]. Hanaoka Seishu no Tsuma written by Ariyoshi, although not directly included in this category, concentrates on a central character whose biography is told by a sympathetic narrator. As illustrated in the following quote.

Alongside Miru in the room had been a spotted dog called Kumomaru and a ginger one named Uzuichi. Bothe had been force-fed with food and drugs and slept with legs outstretched. Was it Kae's condition alone that aggravated her highly emotional nature? Perhaps. In any case, she had constant nightmares. On many a night she awakened to find Otsugi trying to comfort her. (p. 86)

\subsection{The Color}

Novel's color is a certain strong impression caused by a novel, which often involves a certain thematic tone. Historical novels, like other genre of novels, can also have certain colors. Historical colors emerge on Hanaoka Seishu no Tsuma through several historical figures, medical equipment, and classic medical books, which are mentioned in parts of the novel to explain the story. The utterance of the historical figures in the medical field and the excerpts of classic medical records in the novel are intended to support the narrative needs developed by the author. This is illustrated in the excerpt of the novel as follows.

"Dr. Yamato taught the same surgical procedures as the old Dutch physician, Caspar. All the instruments I've brought with me come from Holland. Some, I'm sure, will even impress you, Father. They're quite different from your Spanish ones. 
"Well, both Dr. Yamato and his former teacher Dr. Kensui claim that for a successful operation the surgeon must consider every aspect of his patient's anatomy and not merely the local symptoms in the problem area. The idea is to search for basic causes, which after all is what makes medicine a science. In order to gain a broader perspective, I also studied under Dr. Yoshimasu, a Chinese specialist." (p. 50-51)

Historical colors in this novel, illustrate elements of historical reality. According to Lukacs [7], the historical reality that appears in historical novels can be seen through the existence of elements of historical authenticity, historical faithfulness, and authenticity of local color.

As well as historical colors, the realist colors are quite strong shown in this novel, through the description and the considerable number of figures. The embodiment and reconstruction of Japanese 18th century socio-cultural life displayed through the portrayal of the activities of the characters as it was in the Edo era. This is seen in the following quotation.

Now, the Hanaokas kept some looms on the veranda and a spinning wheel in a nearby storage area. When their chores were done, the older girls, skilled at weaving, went off and worked at the looms without a break until dinner. Their special weave used dyed threads that Kae surmised must have come from the Matsumoto. At first Kae thought the sisters were making clothes for their future marriages. Tami had once told her that a farmer's daughter had to put together her own wardrobe, after which any extra fabrics she had were sold to get money for her dowry. "They may need silk garments", Kae wondered, and considered giving them some of hers.

But she soon discovered that they were not working for their own interests. Every so often a merchant from across the river collected finished rolls of cloth from each house in Hirayama which he sold to the city dwellers of Sakai. On his return trip he brought his village suppliers either cash or merchandise. Kae observed that the Hanaokas never sought remuneration in the form of goods for the girls. They asked only for money, which Otsugi saved until she had a certain sum. The entire amount was then sent to Umpei through another vendor or through someone at the dye works who was planning to go to Kyoto on business. (p. 39-40)

The ideological color of female oppression in the Edo period appears to be strongly demonstrated in Hanaoka Seishu no Tsuma. Although the story of competition between Otsugi and Kae in seizing Seishu's attention seems to be very dominantly described in this novel, but it is only as an outer layer to reveal the real core of the problem around the oppression experienced by women under the confines of the Japanese patriarchal system. The two women started a path of self-destruction together when they competed for the attention of Seishu, the men who were their respective husbands and sons. Both are involved in a competition to put themselves forward as guinea pigs in the experiments that are being carried out by Seishu. Kae and Otsugi's actions, which illustrate the form of their lives, were an inevitable result of the burden of social forces that weighed on both of them. They could not completely free themselves from the constraints of the current social order which 
demanded women to support, even willing to sacrifice themselves for the sake of their husband and family. The following is one excerpt from the debate between Otsugi and Kae.

"You can't mean that! It's I, your daughter-in-law, who would not be able to face the world if I permitted you to take the medicine. How could I be happy afterwards? No, I will assume the responsibility no matter what".

“Absolutely not. I haven't much longer to live. I have outlived my husband. And I have no regrets. When Okatsu died I really wished to go with her since life can hold no further pleasure for me. All my children have grown up. Umpei has a splendid wife. Now I prefer to join my husband in the grave rather than continue in this house which is run by a younger generation. If my body could be of some use to my son, I would be more than grateful. You still have the important task of producing an heir for this family. Until then your body must be well cared for".

"They say that a childless woman, or one who hasn't borne a male after three years, should leave. I am such a useless woman-only one girl. Why do I deserve to live? I insist on being the subject. How can I let an older woman go through such an ordeal?" (p. 106-107)

Along with historical, realist and ideological colors, psychological colors are also displayed in this novel. The psychological color in this novel is focused on psychological problems in the form of inner upheaval of the female character, Kae. Mental events such as Kae's musings and daydreams are plentiful in this novel. The series of emotions and confusion of feelings buried by Kae in dealing with and responding to her mother-in-law's hostility was highlighted. The root of all the tension, conflict, and hatred that formed the series of events that appeared in this novel was the hidden competition that occurred between Kae and Otsugi. Both of them wanted to show their respective roles as ideal women in front of Seishu to get his attention. The following is a quote that illustrates the inner turmoil and conscience of Kae.

...she concluded that Otsugi's seeming thoughtfulness concealed a carefully calculated plan. Besides, if the newborn was to be a full-blooded Hanaoka, was she, Kae, the bearer of this child, to remain an outsider forever? Were her teeth, tongue, and stomach nothing but pestle and mortar, merely the instruments to feed the Hanaoka heir? She felt physically repelled by the food. In the first place, she sensed Otsugi's solicitude was a curse in disguise; in the second, she imagined that the Hanaokas would stuff her for nine months until the baby arrived, and then expect her to die; and lastly, she associated her fate with the numerous dogs and cats who had been buried under the persimmon tree. (p. 77)

In the above quotation, Ariyoshi seems to intensify the impact of her words by using a metaphor. Kae sees herself, equated to an animal used in the Seishu experiment, which is useful for the family only in what she can contribute to Seishu's success. In this novel, Ariyoshi describes the inner upheaval of the main character in response to the demands addressed to her as a woman. 


\subsection{The Writer}

Ariyoshi Sawako was born on January 21, 1931 in Wakayama Prefecture and died August 30, 1984 in Tokyo. She grew up in the famous southern area of Osaka and its honorable tradition. This environment sparked her interest in traditional arts and theater [10]. Ariyoshi studied literature and theater at Tokyo Women's Christian College from 1949 to 1952. After graduating she joined staff of publishing companies, contributed to literary journals, worked for theater dance groups, and began publishing short stories, as well as scripts for stage, television and radio. In 1959, Ariyoshi won a Rockefeller scholarship to study for one year at Sara Lawrence College in New York City. She continued her studies of the performing arts, a field that she has been interested in since her days at Tokyo Women's College. Based on this short biography, Ariyoshi is an educated woman writer and develops her creativity through many performing arts activities and writing activities which can be seen from her high amount of works.

J. Thomas Rimer acknowledged the general opinion that Ariyoshi Sawako was one of the best female Japanese writers after the war, but argued that the description was inadequate because it failed to define and accommodate the extraordinary talents she possessed. Ariyoshi is a very productive woman writer. In her relatively short age, she produced 100 short stories, novels, dramas, musicals, and film scripts. In the academic journal Monumenta Nipponica [11] it was mentioned that Ariyoshi's literary style, at times poignant but never sentimental, her perceptive psychological insights and descriptive powers, and her skill in plot construction, earned her both popularity and esteem, and a number of her novels became best-sellers. Ariyoshi's interest in social and environmental issues surfaced in a number of her novels and created a considerable impact in Japan. Her way to raise controversial topics and arouse public awareness about Japan social problems, also seen from Hanaoka Seishu no Tsuma's popularity, which is widely translated into several foreign languages. Through this novel, she was marked as a leading woman writer in Japan and a best-selling author in France, according to The Japan Times [12]. In her review on Ariyoshi's novels, Pfeiffer [13] explained that Ariyoshi exposes the demands made on Japanese women, both by others and themselves, and reveal their strength. In a forceful yet quite voice, she develops vivid female characters, who make their marks in a male-dominated world, just as Ariyoshi herself makes her mark on the Japanese literary world by combining her terse, graceful writing style with poignant social criticism.

The choice of using historical subjects in Ariyoshi's work can be read and interpreted as her attempt for questioning the nature of social conditions in Edo era, especially regarding women, while offering a reflection on the lives of Japanese women. By not ignoring the ties to the historical truth reflected in her novels, she seeks to provide a picture of the past as well as the ideas of the author in viewing the past from her perspective as a woman. It can be said that Hanaoka Seishu no Tsuma written by Ariyoshi Sawako reflects the spirit of the era, and the author's "dialogue" with it.

\section{Conclusion}

By taking the main character of the wife of Dr. Hanaoka Seishu, the novel follows the Lukacs version of the historical convention, where the historical figure occupies the main character with its character and appearance is adjusted to Ariyoshi's interpretation as the 
author. The plot in this novel flows progressively in a simple form. The story runs in a fast rhythm, which is marked by the number of the time leaps used in the story. Though, small events with many descriptions fill the composition in this novel. The novel is dominated by ideological colors which describes the oppression of women in the Edo period and psychological colors focused on psychological problems of women's inner turmoil, aside from historical and realist colors.

Ariyoshi Sawako is an educated Japanese woman writer, and has a great interest in social issues, thus affecting the ideological color of her work. With the strong ideological color on it, this novel can be said as a counterweight to various narratives of Japan past social conditions which dominantly composed from the literary works of male writers.

\section{Conclusion}

I kindly acknowledge financial support from Department of Japanese Language and Culture, Universitas Al-Azhar Indonesia, who provided seminar funding support for author as speaker in STRUKTURAL International Seminar 2019, Faculty of Humanities, Universitas Dian Nuswantoro, Semarang, Indonesia.

\section{References}

[1] S. Orbaugh, "The Body in Contemporary Japanese Women's Fiction,” Woman's Hand Gend. Theory Japanese Women's Writ., pp. 119-164, 1996.

[2] Y. R. Subakti, "Revitalisasi Pembelajaran Sejarah Melalui Kajian Novel Sejarah," in Prosiding Nasional Sejarah Indonesia: Cerdas Humanis di Era Digital, 2017, pp. 298-310.

[3] T. Todorov, "Tata sastra," 1985.

[4] S. Rimmon-Kenan, Narrative fiction: Contemporary poetics. Routledge, 2003.

[5] A. Djokosujatno, "Novel Sejarah Indonesia: Konvensi, Bentuk, Warna, dan Pengarangnya," Hubs-Asia, vol. 10, no. 1, 2010.

[6] A. Fleishman, The English Historical Novel: Walter Scott to Virginia Woolf. Berghahn Books, 1972.

[7] G. Lukács, J. Clairevoye, and L. Goldmann, La théorie du roman. Gonthier Paris, 1963.

[8] D. L. Kotler, H. Hirose, C. J. Yeo, and S. W. Cowan, "Dr. Seishu Hanaoka (1760-1835): Surgeon, Pharmacist, and Anesthesiologist," Am. Surg., vol. 80, no. 1, pp. 7-9, 2014.

[9] U. Sachidanand, "Social change in Japan and the place of women: a study of women protagonists in Ariyoshi Sawako's writings."

[10] W. J. Nakanishi, "Desperate Housewives in Modern Japanese Fiction,” Electron. J. Contemp. Japanese Stud., 2007.

[11] Winter, "Ariyoshi Sawako, 1931-1984," Monum. Nihon., vol. 39, no. 4, p. 453, 1984.

[12] N. Gattig, "The Doctor's Wife' fictionalizes the life of Japan's pioneering anesthetist," The Japan Times, 2016. .

[13] C. S. Pfeiffer, “The Doctor's Wife, The River Ki,” J. Japanese Trade Ind., pp. 56-57, 2002. 